\section{Artful communication}

John Morton

The Prehistory of the Mind: A Search for the Origins of Art, Religion and Science. By Steven Mithen. Thames and Hudson: 1996. Pp. 288. £16.95, \$27.50.

STEVEN Mithen has produced a dramatic reconstruction of how the modern human mind has evolved over the past few million years. He writes with clarity and verve, and I have already dined out on my new-found ability to sort out which species of Homo is which and on Mithen's wide-ranging speculations on what properties of mind are needed for basic human activities. Technical discussions are placed in the extensive end-notes and are not allowed to impede our race through prehistory. The core belief is that only archaeology can help us to understand the origins of the modern mind. The archaeology is used to specify what the minds of our ancestors must have been like.

The book starts with an overview of our fossil history. Mithen then picks out some recent writing in cognitive and developmental psychology. His reading here has been spotty and, although some of his informants are put to good use, others are less well integrated. However, he emerges with a framework of specialized intelligences: linguistic, technical, social and natural history. These are used in the analysis that follows of the chimpanzee's mind and those of our forebears.

In this analysis, chimpanzees have general intelligence as well as specialized domains of social intelligence and natural history. Their expertise at finding tools for the job in hand is seen as a manifestation of general intelligence. Their inability to instruct their young in tool use is seen as a manifestation of the lack of communication between social and general intelligence. The same is true for Homo habilis, who has been able to manufacture limited tools - owing to the development of technical intelligence - and exploit animal carcasses, but there is no imposition of social information on the tools.

Homo erectus had the ability to manufacture symmetrical hand-axes, demonstrating an advanced technical intelligence. But they ignored other materials such as bone and antler, they had only generalpurpose tools, there were no multi-component tools and there was little or no cultural variation. The Neanderthals were a little further advanced technically, but managed to survive in a harsh environment owing to their advanced naturalhistory intelligence, which enabled them to track and trap game.

Mithen deduces that they must have had high social intelligence because they cooperated but, on the basis of the archaeological evidence, that they had little social structure. The solution to the paradox is that the technical, naturalhistory and social intelligences have cognitive barriers between them. Modern humans, with interconnected intelligences, would sit round the fire in a group, manufacturing or mending their tools and engaged in conversation. Mithen thinks that the evidence in favour of the Neanderthals having language is compelling, but concludes that the use of language must have been restricted to the social domain. No one would have given instruction on how to make tools. Above all, the Neanderthals had only a "rolling, fleeting ephemeral consciousness about their own knowledge". There was no introspection - and no art or ritual.

In the modern mind, all the kinds of intelligence are connected. The early human mind could interpret natural symbols such as hoofprints, communicate intentionally in social matters and produce artefacts. But all these were isolated abilities, and it took the modern human mind to be able to "create artifacts and images with symbolic meanings as a means of comMuseum Press, £25. munication - i.e. art". Anthropomorphism and totemism are the cross-product of thinking about animals and thinking about humans - again, only possible in a mind where natural-history and social intelligence can communicate. Racism, thinking about people as objects to be manipulated, is the product of thinking about objects to be manipulated (technical intelligence) and thinking about people.

Finally, agriculture arises from four aspects of the change in the structure of the mind: specialized tools from the interaction of technical and natural-history intelligence; use of animals and plants from the integration of social and natural-history intelligence; domestication of plants and animals from integration of social and natural-history intelligences; and the manipulation of plants and animals from the combination of technical and naturalhistory intelligences.

It is a pity that Mithen made little attempt to put his ideas in relation to those in Origins of the Modern Mind by Merlin Donald (Harvard University Press, 1991), which, as the title indicates, has a similar objective and uses the same methods of integrating data and ideas from psychology and archaeology. Comment is relegated to a footnote, where Mithen, to give him credit, does "highly recommend" that readers also read Donald. Mithen comments that the complexity and variability of the

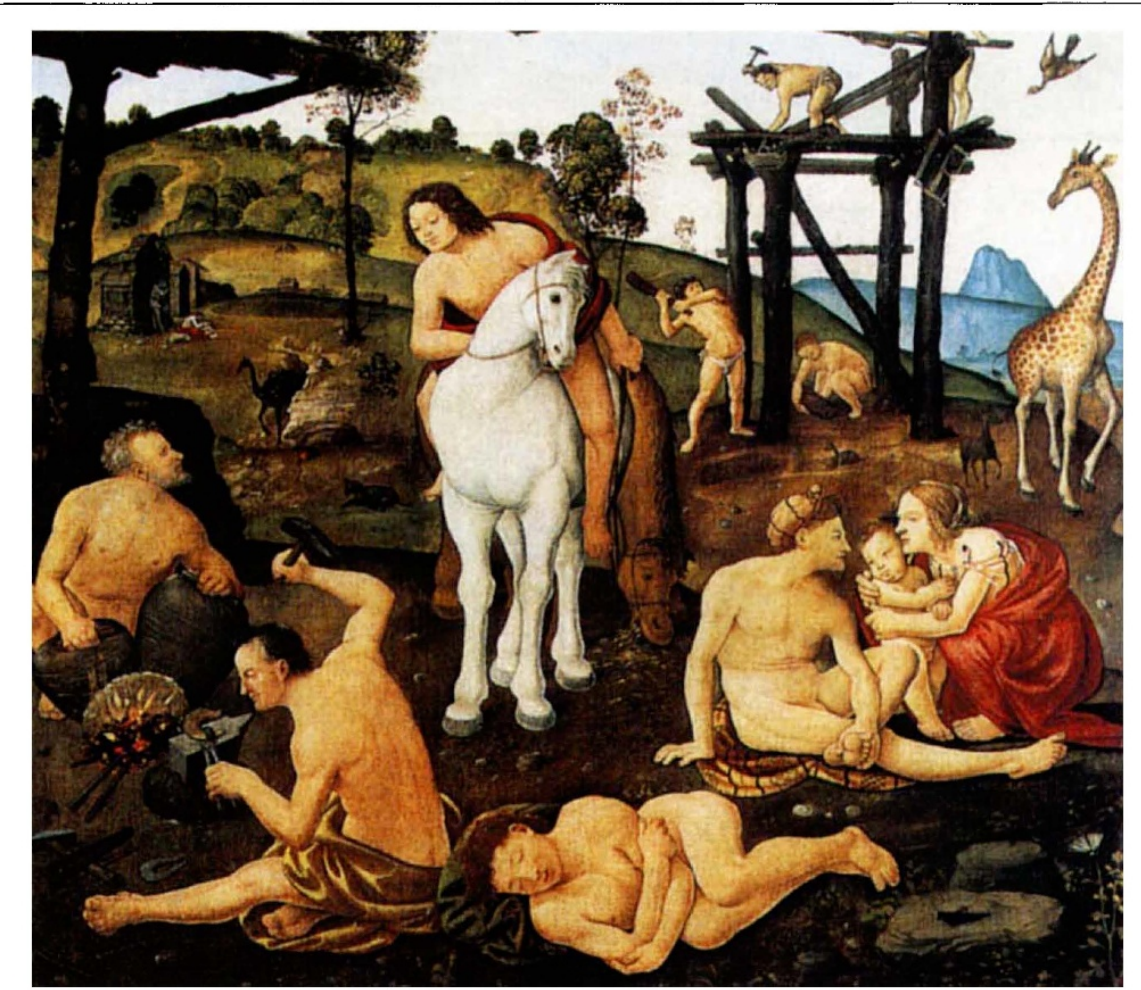

VULCAN at his forge teaches humans the arts that distinguish them from animals. This painting by Piero di Cosimo, illustrating a Renaissance theme in anthropology, is one of many pictures in The Discovery of the Past: The Origins of Archaeology by the French scholar Alain Schnapp. The book interweaves history, art and literature to trace how Europeans, from antiquity to the age of Darwin, explored their past. British 
the archaeological data are insufficiently appreciated in Donald's book. The subtitle of Mithen's book - "A Search for the Origins of Art, Religion and Science" - is a clear come-on for the general reader, but Mithen stops well short. Donald, on the other hand, who goes on to consider literacy and its effects, and the use of artefacts as memory aids, goes much further down this line.

Of course, as a psychologist, I believe all the archaeology Mithen lays before us, but the psychology remains that of an enthusiast. His notion of acceptable evidence will strike most psychologists as odd. He quotes Oliver Sacks on his impression of an autistic whose "sense of animals' moods and feelings is so strong that these almost take possession of her, overwhelm her at times".
This is taken as "good evidence that the mind has a specialized device for learning about the natural world". Here, as in other examples, Mithen fails to distinguish reliably between genetic evolution and cultural evolution, between specialized cortical devices and the consequences of massed learning of a topic. He also seems unaware of the need to make clear distinctions between specialist skills and the sometimes very abstract specialist cognitive abilities that underlie these skills.

In the end, though, this is a very good read, packed with well-presented information and provocation.

John Morton is at the MRC Cognitive Development Unit, 4 Taviton Street, London WC1H OBT, UK.

\section{Sport on the brain leads to pain}

\section{John C. Marshall}

Why Michael Couldn't Hit, and Other Tales of the Neurology of Sports. By Harold L. Klawans. W. H. Freeman: 1996. Pp. 308. \$22.95.

AN intimate relationship between sport and cognitive neurology has existed since the inception of the discipline. When the 26-year-old Baron Edouard de Rampeau was injured in a fencing accident in 1807 , he was referred to the eminent physician Franz Joseph Gall (1758-1828), and a discovery about the brain ensued.

The broken tip of the fencing foil had penetrated to the posterior part of the anterior left lobe of the brain. De Rampeau continued to recognize objects and use them appropriately but, Gall reported, "the memory of names was wholly extinguished". The left frontal region therefore came to be seen as crucial to the exercise of the language faculty.

In Gall's day, limited brain damage in previously healthy young adults was commonly due to the foil, whether used in sport, jest or earnest. Gall eagerly seized on such cases, regarding them as better suited for showing localized functions of the brain than the more extensive effects of apoplexy (stroke) in the elderly.

Fencing does not figure in Harold Klawans' latest collection of neurological essays for the layman. But boxing does. For the most part, boxing, the only 'sport' whose purpose is to cause chronic progressive brain damage, produces diffuse neuronal injury leading to dementia. In some instances, however, the lesions can be more restricted, although their effects on action, cognition and personality are not necessarily less severe. Klawans' chapter on Muhammad Ali is both a fine tribute to 'The Greatest' and a lucid introduction to the functions of the substantia nigra, damage to which was reponsible for Ali's post-traumatic Parkinsonism. The consequences of the speed of Ali's lip were, if anything, even more disastrous than the sad shuffle of his later years.

Klawans is somewhat ambiguous in his own attitude to boxing. He manages to regard it as "one of our eternal verities", while reminding us that two millennia ago the Emperor Augustus "put an end to boxing because the sport was ruining too many prospective soldiers".

Klawans is also strangely unsympathetic to Primo Carnera, the only native Italian to win the world heavyweight championship. Medically, Klawans is excellent on how Carnera's giantism (acromegaly) was caused by a tumour of the pituitary gland. But he fails to appreciate Carnera's outstanding intelligence: most of Carnera's fights were won by his arranging for the Mafia to pay his opponents to fall over, and he ended his career playing bit-parts in Hollywood movies.

It is a pity that such sensible career-planning is so little stressed in these essays. Top athletes presumably require superior strategic intelligence at least as much as they need strength and visuo-motor coordination. The issue arises only in the chapter on Roger Bannister, where it is emphasized that the four-minute mile was achieved by serious thought and a profound knowledge of physiology rather than by intrinsic talent and intensive application.

Even in these days of supercharged professionals, the thought of Bannister training for half an hour a day "during his lunch breaks from his duties at the hospital" can still bring a tear of cultural joy to the amateur English eye.

For the rest, the sport in Klawans' book is resolutely American, although the diseases are international: baseball and occlusion of the right subclavian artery when pitching, volleyball and Marfan's syndrome (a disorder of connective tissue), basketball and tics (Gilles de la Tourette's syndrome), American football and myasthenia gravis (a disease of the neuromuscular junction), golf and the dystonias (abnormal, involuntary movements that "move part of a limb into an untoward position and keep it there")... and more and more and more baseball injuries.

Klawans' ability to describe complex medical issues in understandable language is peerless. But the jargon of baseball defeated me to much the same extent that cricket cannot be explained to Americans. I did, nonetheless, come away with the strong feeling that many modern sports (and baseball in particular) are extremely dangerous.

Perhaps we should revert to duelling, a comparatively safe sport and one whose underlying code of honour might enforce higher moral standards in public life.

John C. Marshall is in the Department of Clinical Neurology, University of Oxford, Radcliffe Infirmary, Woodstock Road, Oxford OX2 6HE, UK.

NATURE · VOL $383 \cdot 31$ OCTOBER 1996 